\title{
"They are Scared of Me": Black Male Perceptions of Sense of Belonging in U.S. Public Schools
}

\author{
Jennifer Grace \\ University of Houston-Clear Lake \\ grace@uhcl.edu
}

\begin{abstract}
Using a Critical Race framework, this study examined black male perceptions of their sense of belonging in U.S. public schools. The author conducted semi-structured interviews with ten black males who had been expelled from schools. Findings reveal perceptions of a stark discrepancy in the quality of education provided at schools that are predominantly black vs. schools that are more racially diverse. Furthermore participants describe school as a hostile environment for black males citing microaggressions, isolation, and verbal abuse as indicators. Based on the findings, practical recommendations for supporting the educational experiences of black males are offered.
\end{abstract}

\section{Introduction}

Current advocates in education reform tout a promise of educational equity. While educational equity is not always easy to define, it is often framed with regard to student achievement outcomes. Despite decades of pushing for equity and higher standards, American education's racial disparities persist in academic results and opportunity and access for black and brown students (Howard, 2019). The Schott Foundation (2015) indicates that only 59\% of black males are graduating high school. Low graduation rates among Black males are mainly due to a host of factors including access to quality instruction and curriculum (Connor \& Ferri, 2005; Greer, Clay, Backmon-Bologun, \& Lougue, 2018), and harsh discipline policies (Gregory, Skiba, \& Noguera, 2010; Gregory, Skiba, \& Mediratta, 2017; Toldson, McGee \& Lemmons, 2015) that function as barriers to successful school matriculation. Standardized test scores and graduation rates measure academic performance within this context. These inequities are suggestive of a bigger problem that requires a more in-depth examination of systemic barriers that affect black males in schools. It is critical to examine these experiences from the students' perspective who can share their perceived systemic barriers that hinder success and contribute to school pushout. The purpose of this study was to take a Critical Race theoretical approach to an understanding of the educational experiences of black males who have been pushed out of school, as voiced by the students themselves.

The phenomenon of black males not completing high school extends beyond being an educational crisis and has detrimental implications for other quality of life indicators. Disparities in education are linked to inequalities in the U.S. criminal justice system in what is referred to as the School to Prison Pipeline (Alexander, 2010; Clemson, 2015). In many school districts, in addition to inequalities in academic programs, repeated out of school suspensions often lead to expulsions from schools. This link is vital to note since expulsion is considered a factor linked to 
incarceration (Alexander, 2010; Booker \& Mitchell, 2011; Clemson, 2015). Due to these projected outcomes and correlations between not finishing high school and incarceration, it is imperative to comprehensively understand black male students' schooling experiences to increase opportunities for success for them. In the current study, I interviewed ten black males who had been expelled from school about their perceptions of how race and racism impacted their educational experiences. The participants spoke openly about race, access, opportunities, sense of belonging, and relationships with teachers. This qualitative research study allows educational leaders to view this issue from a student viewpoint and, in doing so, ultimately impacting change for these students life trajectories. As referred to by researchers (Jackson \& Moore, 2008; Noguera, 1997), the crisis of the black male warrants probing the experiences black males have had in school. In particular, black males who have been excluded from school make for the most resourceful way of gaining critical information. The study's findings can create a counter-story to dispel deficit thinking and inform educational leaders, policymakers, and practitioners in creating equitable systems and outcomes for black males in K-12 schooling systems.

\section{Critical Race Theory}

Critical Race Theory (CRT), the most appropriate framework for studying black male perspectives of their K-12 educational experiences, is intended to investigate and disrupt the relationship between race, racism, and power (Delgado \& Stefancic, 2017). Alexander (2010) writes that racism has shifted from more deliberate discrimination and violence from the Jim Crow era, but instead, it functions passively and systemically rooted in various institutions. Institutionalized racism is expressed in the policy and practice of political and social institutions. The American education system is a prime example of how institutionalized racism is embedded in society, as evidenced by the continued achievement gap and disparate discipline practices. CRT scholars prioritize investigating people of color's lived experiences, as CRT aims to challenge perspectives that exclude racism from the lived experience of marginalized people. CRT is consequently a suitable framework in examining the educational experiences of black males who have been excluded from school and adds a counter-narrative to the literature.

One fundamental tenet of Critical Race Theory is the idea that racism is ordinary and pervasive (Delgado \& Stefancic, 2017; Ladson-Billings, 1998). Racism as ordinary equates to invisibility. If racism is unseen or unacknowledged, it cannot be effectively eradicated (Delgado \& Stefancic, 2017). Colorblindness and phrases such as, "I don't see color" are inherently problematic as they negate the reality of people of color, who are inundated with racialized structures and norms on a day to day basis. Approaching equity in education reform from a colorblind standpoint is dangerous. Taking a colorblind approach to education is not advised by advocates of Critical Race Theory (Ladson-Billings, 1998). Not discussing race and racism leaves educators at a disadvantage in understanding their prejudices and privileges and how they may impact their professional practice. CRT acknowledges that race matters (Dixson \& Rousseau, 2014). Unrecognized indicators of racism only preserve a system in which black and brown students are institutionally oppressed. 
CRT's interest convergence principle asserts that racism works to advance the interests of both elite and working-class whites (Delgado \& Stefancic, 2017). Derrick Bell (1980), one of the original CRT scholars, explained, "The interest of blacks in achieving racial equality will be accommodated only when it converges with the interests of whites" (p. 523). Within this context, given the historical persistence of disparities in educational outcomes for black males, it is perceivable that disrupting inequities that negatively impact black males in school does not advance the interests of the white elite or white working-class thus allowing the persistence of the invisibility of race in educational policy and practice. This concept underpins the notion that widespread education reforms such as school choice and strict accountability measures, which are shrouded in colorblindness, have not been successful in enhancing outcomes for black males. Another tenet of CRT is race as a social construct or race as a creation of social relations (Delgado \& Stefancic, 2017). This tenet is further understood through the idea of the social construction of whiteness or whiteness as property, mirrored in present-day policy and practice in U.S. schools that lack cultural responsiveness and reinforce "whiteness" (Jones, Mixon, Henry, \& Butcher, 2017; Khalifa, 2018; Kosleski, 2018).

An additional tenet of CRT that fits this study is intersectionality or the idea of overlapping or multiple identities (Delgado \& Stefancic, 2017). Within this study's context, it is essential to note the lived experience of being male and black. The final principle of CRT emphasizes voiceof-color or the idea that "minority status brings with it a presumed competence to speak about race and racism" (Delgado \& Stefancic, 2017, p. 11). Ladson-Billings (1998) previously referenced this as counter-storytelling or a narrative of experiences provided by those from marginalized communities. Counter-storytelling centers race in examining the lived experiences of people of color and elucidates assumptions of those dominant groups that are masked by privilege (Solorzano \& Yosso, 2002). This study's qualitative structure provides for such discussions to understand the schooling experiences of black males from their viewpoint. A Critical Race theoretical framework examines these issues from the perspective of the student. It informs education leaders and policymakers with information that may lead to disrupting institutionally racists structures that act as systemic barriers in education for black males.

\section{Literature Review: Schooling Experiences of Black Males}

\section{Access Denied}

The opportunity gap in education refers to access to quality school resources, teachers, and curriculum for certain students (Carter \& Welner, 2013). The most notable example of inequitable access is that black males are more likely to be taught by uncertified or low performing teachers (Vivian, 2017). Additionally, black male students often have zero to low enrollment in Advanced Placement courses and are overrepresented in special education programs (Connor \& Ferri, 2005; Sacks, 2019). As it related to special education diagnosis, black males are also more likely to be labeled as having a cognitive disability or emotionally disturbed (Smith, 2005). More school leaders and policymakers should consider the expectations they have for black males and create ways to have access to better teachers and more rigorous courses. 
Another factor that impacts opportunities for black males is standardized testing. Standardized tests are used to track students throughout their K-12 journey (Carter \& Welner, 2013; Donner \& Shockley, 2010). The practices of standardized testing and tracking have long been attributed to the marginalization and exclusion of students of color ( Carter \& Welner, 2013). Donner and Shockley (2010) wrote, "misalignment between standards-based assessment and instructional practice suggest that students currently situated at the low end of the academic achievement gap will be further marginalized" (p. 55). There is a credible link between academic achievement and incarceration (Alexander, 2010). These are essential factors to consider while trying to appreciate how the school to prison pipeline works and how it particularly impacts black male students.

As noted above, ability tracking is a dangerous practice utilized by schools that often negatively impacts black males (Smith, 2009; Stanley \& Chambers, 2018). Researchers (Stanley \& Chambers, 2018) explain that academic stratification has historically affected minority students and begins as early as elementary school and follows a student for a lifetime. This phenomenon can also be described as labeling. Labels follow students throughout their educational experiences, and minorities are disproportionately impacted (Marsh, 2018). Smith (2009) asserts that placing students on lowers tracks as early as elementary school leads to not having access to high-quality instruction, leading to disruptive behaviors. Practices, as outlined in this section, are examples of institutionalized racism and often coincide with disparate discipline practices that also disproportionately impact black males.

\section{Disproportionality}

Disproportionately harsh discipline practices have historically impacted black males (Children's Defense Fund, 1975; Clemson, 2015; Mallett, 2017; Skiba, Arredondo, \& Williams, 2014; Welch \& Payne, 2010). With the increase in zero-tolerance policies and police officers in schools, a pipeline has been formed that introduces students to the court systems at a young age, for a majority of minor offenses that could have been dealt with by the school (Mallett, 2017; Smith, 2009). This occurrence highlights a general issue that the pipeline takes students out of the classroom more often with zero-tolerance policies than correcting students with a growth mindset to help them change. These zero-tolerance policies also produce substantial consequences for minor infractions in the school setting.

Zero-tolerance policies were implemented in schools nearly 30 years ago to keep weapons and drugs off school campuses (Boyd, 2009). Over the years, the idea of Zero Tolerance has expanded in such a way that might remove students from school for minor offenses including being tardy, skipping, and what may be perceived as disrespect (Daly et al., 2016). Zero Tolerance also creates an environment in which referrals are at the educator's discretion, and perceptions play a huge part in that (Daly et al., 2016). Teachers' perceptions of students are essential to consider given that black males are suspended three times more than white males and other peers for discretionary offenses such as disrespect and disruptive behavior (Losen \& Skiba, 2010; Toldson, McGee, \& Lemmons, 2015). Practices such as those previously mentioned have lessened the need to develop correct classroom management and cultural competency skills because students can instantly be referred to the office and removed from the classroom. 
Zero tolerance policies have only worsened disparate discipline practices disproportionately affecting black males. Researchers (Daly et al., 2016; Rocque \& Paternoster, 2011) determined that these policies negatively impact black males in elementary school and like tracking, have lifelong consequences. Like academic labels, behavioral labels follow black males functioning as an early introduction to the school to prison pipeline. This practice becomes a vicious cycle for black males as research has determined that students who are suspended are susceptible to academic failure, dropping out, and eventually incarceration (Skiba et al., 2011; Slaughter, 2019).

Zero tolerance policies have created school environments that mimic incarceration institutions (Clemson, 2015). These environments become breeding grounds for minority students, special education students, and students from poverty backgrounds to be removed from school or drop out (Clemson, 2015; Daly et al., 2016; Noguera, 2003). Noguera (2003) claims that teachers have negative perceptions of these students and often perpetuate their labels, which impact their ability to manage the classroom effectively. Unnecessary referrals and suspensions only further marginalize these students. Being removed from the classroom also means less instructional time, which exacerbates disparities in academic achievement.

Researchers (Sacks, 2019; Skiba, Arredondo, \& Williams, 2014) assert that increased repeated disciplinary referrals are correlated to involvement in the juvenile justice system. Once introduced to the criminal justice system, it is nearly impossible to exit the cycle (Alexander, 2010; Smith, 2009). These incidents' disproportionate nature calls for an examination into facets of institutionalized racism within the educational system. Several studies (Losen \& Skiba, 2010; Skiba et al., 2011; Skiba, Arredondo, \& Williams, 2014) examine disparate discipline practices and their impact on black males, few explore the issue from the perspective of students themselves.

\section{Methodology}

The purpose of this study was to gain new perspectives to add to the dialogue about the educational experiences of black males. A qualitative approach is well-suited for this study because qualitative research is designed to gain a deep understanding of a specific event (Creswell, 2013). Specifically, phenomenology is essentially the study of the lived experience of the lived world (van Manen, 1997). The phenomenological approach lends itself to the task of understanding participants' lived experiences specifically related to their educational experience and the meanings they attach to them (Creswell, 2013; Glesne, 1999; Ramsook, 2018). The participants' descriptions of how they perceive race and racism's impact on their educational experiences embody the tenets of Critical Race Theory. The benefit of in-depth interviewing is that it converges on meanings that life events have for individuals and how it guides their future actions (Creswell, 2013). Individual interviews are appropriate for this study because this method is aligned with the counter-storytelling tenet of CRT and allows the participants a platform to communicate their experiences (Delgado \& Stefancic, 2017).

Previous research (Casanova et al., 2005; Coley \& Baker, 2013; Jeynes, 2005; Orfield \& Lee, 2005; Peske, 2006; Somers, Owens, \& Piliawshy, 2008; Williams et al., 2002) has explored

Journal of Contemporary Issues in Education, 2020, 15(2), pp. 36-49. 
various angles, including but not limited to socio-economic implications, parental involvement implications, and peers of the students, and high achieving students to attempt to explain vast disparities in the academic achievement of African American males when compared to their white peers. Few researchers have taken the approach to examining the educational system through the experiences of those who have succumbed to exclusion from traditional settings altogether.

\section{Participants}

Interviews with 10 African American males who had been excluded from school were analyzed for this study. Participants who met the following criteria were chosen to be a part of this study: African American, male, expelled from a public school within the last 1-3 years, and currently enrolled in a disciplinary alternative educational setting. The participants' ages ranged from 15 to 18 years old. Five of the young men were considered seniors in high school, one was a junior, and four were considered sophomores in high school. Eight of the young men were expelled from a public charter school in New Orleans, while two were expelled from a traditional public school. Eight of the young men also participated in football and basketball at their previous school setting and the current setting. All of the young men had post-secondary goals beyond completing high school. Two of the young men aspired to join the military immediately following graduation; one young man planned to attend a technical or community college. Seven of the young men had aspirations to attend a four-year college or university upon completing high school. To gain a deeper understanding of how these young men perceived their educational experiences, they were interviewed individually.

\section{Data Collection and Analysis}

This study examined the role of racism within institutional structures in place that incapacitate black males on their educational journey in public schools. As outlined by Moustakas (1994), the procedures for data collection consist of identifying a phenomenon to study, bracketing out one's experiences, and collecting data from several persons who have experienced the phenomenon. To recruit participants, I emailed the principal of the alternative school detailing the study's purpose and proposed procedures. The principal then connected me with the counselor who was able to identify some young men who met the qualifications and who would be willing to participate and share their stories. I met with the young men to speak to them about the intent of this research and procedures, benefits, and risks. The participants' descriptions of their K-12 educational experiences were obtained through in-depth interviews with each participant. I scheduled at least one meeting with each participant and conducted individual interviews designed to last about 60 minutes with participants. An interview guide was developed, adapted, and utilized to gather data from participants. The interview guide was used to ensure a standard interview process for each participant. The semi-structured interviews lasted one hour in the participants' school setting. It is important to note that only one formal interview took place with participants due to the transient nature of the alternative environment. Participants could be enrolled anywhere from 10 days to 1 year. These interviews were audiotaped, transcribed verbatim by me, the researcher, and analyzed for categories that further illustrated the research problem.

Data analysis is described as the process of transforming succinct statements into an 
overall description or explanation of a given phenomenon (Creswell, 2013). As it relates to data analysis in a phenomenological study, phenomenologists are focused on the crux of an experience. Phenomenologists are concerned with showing how complex meaning is built out of simple units of direct experience (Merriam \& Grenier, 2019). To accomplish this, Merriam and Grenier (2019) assert that the researcher must bracket their previous experiences to analyze and understand the crux of the experience from the participants' perspective. As a black educator, I was very close to the issue by having worked with black males. It was essential to begin a reflexive diary to process my thoughts, feelings, reactions, and biases. I engaged in this bracketing technique to remove "my experiences" from the analysis process, which enabled me to focus on the participants' authentic lived experiences and their interpretations of those experiences. Data were analyzed using modified methods described by Moustakas (1994) in his guidelines for analysis of phenomenological interview data, which includes coding for statements of significance, clustering for units of meaning, and then writing a composite description that provides the essence of the phenomenon in its entirety.

Transcripts were manually coded using the open coding method, which consisted of a line-byline analysis of each transcription and focused on patterns that yielded codes (Maguire \& Delahunt, 2017). Next, I used the codes to search for themes, followed by a review of themes generated. Lastly, I worked to define the themes or explain the phenomenon (Maguire \& Delahunt, 2017). All transcriptions and coding were done manually to avoid errors or overlook some themes that coding software might cause. Coding and themes were validated by having the analysis reviewed by an independent researcher and conducting follow-up interviews for member checking (Burnard et al., 2008; Lincoln \& Guba, 1985).

\section{Findings}

Data collected from the ten black males who participated in the study provide insights into their conceptualizations of institutionalized racism's impact on their experiences. Each thematic category and its corresponding concepts are discussed and supported with quotes and reflections from the participants.

\section{Equity in Access and Opportunity}

Throughout the interviews, participants were asked to describe challenges to success that they have encountered and how they distributed responsibility for those challenges. Participants shared a desire to attain educational success that would grant them opportunities to attend college and begin meaningful careers -opportunities they believed would put them in a position to subscribe to the idea of masculinity - being good providers for their families. Participants felt that as black males, they were permanently relegated to second class citizenship within their school environments which manifested itself in a lack of instructional and material resources in schools such as low-quality textbooks, breadth of course selection, lackluster libraries, and nutritional options, and exposure to academic, extracurricular opportunities. For example, when asked to describe his educational experience, Robert explained the school he had been expelled from as "it doesn't have like as much opportunities as like other top schools. I think if I were at another school I could have been more educated and had more better experiences." Dylan also described the difference between the type of instruction he received vs. the type of education 
those who went to schools that were not predominantly black as, "Seeing the teacher...doing stuff....not just handing out work and making us do it....telling us to write definitions all day or something like that."

The participants shared awareness of schooling experiences for the upper class, white children that facilitated critical thinking, and encouraged creativity. Whereas they were often not afforded a welcoming environment to share their thoughts and express their creativity. All participants expressed a desire to participate in instruction that resembled project-based learning, which allowed them to be active investigators in the learning process. In addition to noting poorly resourced schools, and low-quality instruction, participants also mentioned frustration with not having enough support in learning about post-secondary options and simple things like applying to college and financing it. Participants felt as if they were locked out of being able to grasp "the rules" of how to become successful.

\section{Belonging}

The participants were explicitly asked what does it feel like to be black and male at school. The dialogue provided by the young men gave their perceived sense of not belonging in their school environments due to different practices and policies in place that were fueled by overall negative perceptions of them as black males. When asked to share the challenges they faced in school settings as black males; the participants overwhelmingly described school as a place that was not designed to be a wheel of mobility for black males. Malcolm felt as though schools only deemed black boys as useful if they played football or basketball, "I did neither so it was like the first time he mess up we gon get him because he showing us he not worthy of going anywhere. It's not right." He believed this was evident in inconsistency in disciplinary practices that were also harsher on black males but surprisingly lenient if it were a black male athlete.

Clifford perceived his school environment as one full of low expectations for him, expressing, "Well it feels like....well I have to prove everybody wrong." Theron also did not feel welcomed in school settings citing, "They stereotype us a lil too much. But it's something that's never gonna change sad to say." Brandon believed that black boys are not welcomed in high performing, integrated schools noting, "Like certain people be like oh he black, he don't need to be going to this kind of school and stuff like that." Shakur shared a painful memory of microaggressions based on his hairstyle at one school, "I don't know it's like from the moment I stepped in there...they did not like me. It was the dean he seen me and (twin brother) he called us Cheeto heads because we had lil twists in our hair."

Malcolm also emphasized that black boys rarely have anyone to relate to in a school setting, "It's hard being a black male in school, especially if you have white teachers. Or female teachers that can't relate. School is not for everybody. They try to make it not for black men." Robert shared, "Some challenges black males face in school is like racism or like teachers not really wanting to deal with them...stuff like that." Theron reiterated, "but socially, it's hard to get to know other races because like they are scared of me."

Brandon likened some of his school experiences to jail-like procedures, "They take our phones and we gotta get searched every day. I feel like why we gotta get searched? We ain't in jail. One 
school was like you have to walk in a straight line or you get suspended. We in high school we gotta walk in a straight line?!" Malcolm shared these sentiments, adding, "For example, when the bell rings, we can't talk in the hall. That doesn't make sense to me. We're not disrupting learning because no one is in class if we are transitioning."

These data suggest that labeling, stigmatizing, and shunning black males is pervasive in school environments and often takes place as antecedents that lead to disengagement and pushout. Most of the participants view race and gender as constructs that significantly impact their educational experiences and disciplinary practices. Furthermore, in many instances, students did not feel welcomed at their respective schools, viewing these sentiments and specific discipline policies and practices as barriers to successful functioning as more blatant attempts of school pushout.

\section{Teacher Expectations and Relationships}

In response to being asked how their teachers demonstrated expectations, participants all shared that teachers sent obvious messages about how they perceived black males and their expectations for black males in various ways. Most of the participants articulated that the negative messages that they received from teachers hurt how they felt about themselves. For example, Dylan shared, "I been told 'you ain't gon be s***.' I felt bad, but a lot of people done told me that." Malik offered, "But sometimes I've had teachers tell me I ain't gonna make it nowhere like every day. I was only in 4th grade though, and they'd be flip about it too like go tell them I said it, I don't care." Brandon shared a similar experience, "And they got certain ones who doubt you, and they be like oh you not gon make it past 17 or 18 . Like somebody told me that here last year. I felt bad, like how can you say that like you don't know what I'm doing."

The participants also voiced that teachers' nonverbal actions are the most significant indicators of whether their teacher had high expectations for them. How their teachers carried out instruction in the classroom helped them gauge how their teachers felt about them. Brandon cited, "You know the ones that want you to do something with your life because they teach from when you walk into when you walk out like from bell to bell. A teacher that keeps pushing you feels positive. One that sits down and won't teach you nothing doesn't think highly of you." Brandon added, "You got some teachers who just sit down and say I don't care I'm getting' paid regardless." Participants could tell whether or not their teacher held high expectations based on what they taught (high level, engaging concepts vs. low-level busy work) and how they taught it (the effort the teacher put into creating an engaging lesson plan vs. worksheets, etc.).

Aside from instruction, the participants reiterated the lack of interpersonal relationships between them and their teachers. They believed that often their teachers did not see them as people, but as projects to be fixed or to not bother with altogether. Lack of meaningful relationships with teachers added another layer of isolation for the young men. For example, Malik lamented on not having positive guidance from teachers, "I never had no teacher that really pull me to the side and tell me "you doing the wrong thing" "you can go the right way." Theron and Shakur added by describing their experiences with some teachers as adversarial. Theron elaborated, "Sometimes teachers will get in your face yelling at you...don't talk to me in that tone because I didn't talk to you in that tone. Don't belittle me." Shakur shared, "Somebody called me stupid before, but I didn't care because I know I'm not stupid." The participants believed that teacher 
expectations were heavily influenced by societal perceptions of Black men, thus impacting the nature of their interactions and relationships.

\section{Discussion and Implications}

Study participants described the sum of their educational experiences and the role that they believe race and racism played in school experiences. Participants wanted to shatter the myth that black males lack motivation towards education and academic achievement. The participants all maintained a positive disposition despite daily subtle and blatant attacks on their psyche. All participants showed a strong desire to succeed academically to pursue better outcomes for themselves and their future families. The participants described structural racism and served as living examples of how racism can permeate through institutions like education through public policy, and institutional practices.

In the past when the participants have felt disengaged from school, it was not due to an inherent lack of motivation to succeed or poor perception of self; it was because of schooling environments and practices like disproportionate discipline and inequitable access to quality instruction which made them feel labeled and ostracized or unwanted. All participants noted that their school environments and relationships with teachers, administrators, and other staff had played a significant role in their experiences. Relationships driven by low expectations and poor perceptions influenced both the way discipline policies in their schools were handled and instructional practices in the classroom.

Relating to Critical Race Theory, the participants provide a counter-story that allows educational policymakers and practitioners to take the blinders off and think critically about how black males are marginalized within the current educational landscape. Educators must look at the dynamics of power and privilege. Acknowledging that race matters and racism exists is central to tackling persistent achievement gaps and dismantling oppressive systems in schools that work together to consign black males to second class citizenship. Participant stories collected in this study also emphasize the idea of interest convergence, asserting that black males serve no purpose to educational institutions unless they can benefit those institutions in some way (e.g., through athleticism). Current educational policy and practice send a strong message that black males have no worth and do not fit into the dominant culture's conceptualizations of achievement. Thus real efforts to mitigate achievement disparities have not taken place. Without engaging in courageous and intentional conversations about race and racism, real reform cannot take place. This study lends itself to revisiting the education reform mantra to move beyond discussions about curriculum standards, standardized testing, school choice, and accountability systems. Implications in this study require us to take a more in-depth look at increasing educators' cultural responsiveness and producing equity-focused leaders and teachers.

Based on the findings, I propose several interventions that will support efforts to dismantle structures that oppress black males in schools. K-12 practitioners are urged to pursue development in intercultural proficiency. Educators with the knowledge and attitudes to value cultural differences among students give credence to an educational system designed to serve all students well. Next, it is incumbent upon reformers to shift from a focus on inherently biased 
practices like standardized test performance to anti-racist leadership. Anti-racist school leaders work to dismantle policies and practices (such as hiring practices, curricular decisions, community engagement in the schools, discipline policies, and more) that perpetuate structural racism.

Additionally, educator preparation programs (EPPs) must examine several areas, including recruitment and retention of students of color, to their programs and how they build cultural proficiency and equity-focused practitioners. Making the proposed programmatic changes means EPPs must also examine data, policy, course content, and other areas. This work by EPPs supports the recommended work of K-12 and makes for a cohesive conversation to take place between the two worlds and may even foster more in-depth collaboration.

The participants of this study were high school students who had been expelled. Further research should include examining black males' experiences in middle school and elementary schools using a Critical Race theoretical lens. Ultimately, the U.S. educational system would benefit greatly from reviewing other marginalized groups' perspectives, including black girls, Hispanic or Latinx students, and Native American students. Researchers should also further examine the process and challenges of school districts and educator preparation programs that are currently addressing equity to provide valuable guidance to others who wish to partake in this journey.

\section{References}

Alexander, M. (2010). The new Jim Crow: Mass incarceration in the age of colorblindness. New York: New Press.

Bell Jr, D. A. (1980). Brown v. Board of Education and the interest-convergence dilemma. Harvard Law Review, 518-533.

Booker, K., \& Mitchell, A. (2011). Patterns in recidivism and discretionary placement in disciplinary alternative education: The impact of gender, ethnicity, age, and special education status. Education \& Treatment of Children, 34(2), 193-208. https://doi.org/10.1353/etc.2011.0016

Boyd, T.M. (2009). Confronting racial disparity: Legislative responses to the school to prison pipeline. Harvard Civil Rights-Civil Liberties Law Review, 44, 571-580. Retrieved from http://harvardcrcl.org/wp-content/uploads/2009/07/571-580.pdf

Burnard, P., Gill, P., Stewart, K., Treasure, E., \& Chadwick, B. (2008). Analysing and presenting qualitative data. British Dental Journal, 204(8), 429.

Carter, P. L., \& Welner, K. G. (Eds.). (2013). Closing the opportunity gap: What America must do to give every child an even chance. Oxford University Press.

Casanova, P., García-Linares, C, de la Torre, M., \& Carpio, D. L. (2005). Influence of family and socio-demographic variables on students with low academic achievement Educational Psychology, 25, 423-435. https://doi.org/10.1080/01443410500041888

Children's Defense Fund (1975). School suspensions: Are they helping children. Cambridge, MA: Washington Research Project.

Clemson, C. E. (2015). The prison path: School practices that hurt our youth. Washington, D.C. Roman and Littlefield.

Coley, R. J., \& Baker, B. (2013). Poverty and education: Finding the way forward. ETS Center for Research on Human Capital and Education.

Journal of Contemporary Issues in Education, 2020, 15(2), pp. 36-49.

(c) Author(s), Creative Commons Attribution 4.0 (CC BY 4.0) licence

http:/lejournals.library.ualberta.ca/index.php/JCIE

doi 10.20355/jcie29402 
Connor, D. J., \& Ferri, B. A. (2005). Integration and inclusion-a troubling nexus: Race, disability, and special education. The Journal of African American History, 90(1-2). 107-127. https://doi.org/10.1086/JAAHv90n1-2p107

Creswell, J. W. (2013). Qualitative inquiry and research design: Choosing among five traditions (3rd ed.). Thousand Oaks, CA: Sage

Daly, B. P., Hildenbrand, A. K., Haney-Caron, E., Goldstein, N. E. S., Galloway, M., \& DeMatteo, D. (2016). Disrupting the school-to-prison pipeline: Strategies to reduce the risk of school-based zero tolerance policies resulting in juvenile justice involvement. In K. Heilbrun, D. DeMatteo, \& N. E. S. Goldstein (Eds.), APA handbooks in psychology®. APA handbook of psychology and juvenile justice (p. 257-275). American Psychological Association. https://doi.org/10.1037/14643-012

Delgado, R., \& Stefancic, J. (2017). Critical race theory: An introduction (Vol. 20). New York. NYU Press.

Dixson, A. D., \& Rousseau, C. K. (2014). And we are still not saved: Critical race theory in education ten years later. In Critical race theory in education (pp. 45-68). Routledge. https://doi.org/10.1080/1361332052000340971

Donnor, J. K., \& Shockley, K. G. (2010). Leaving us behind: A political-economic interpretation of NCLB and the miseducation of African American males. Educational Foundations, 24(3-4), 43-54. Retrieved from http://www.questia.com

Glesne, C. (1999). Becoming qualitative researchers: An introduction (2nd ed.). New York: Addison Wesley Longman.

Greer, W., Clay, A., Blackmon-Balogun, A., \& Louque, A. C. (2018). Meeting the achievement needs of California's African American boys. The Journal of Negro Education, 87(2), 169-182.

Gregory, A., Skiba, R. J., \& Noguera, P. (2010). The achievement gap and the discipline gap: Two sides of the same coin? Educational Researcher, 39(1), 59-68. https://doi.org/10.3102/0013189X09357621

Gregory, A., Skiba, R. J., \& Mediratta, K. (2017). Eliminating disparities in school discipline: A framework for intervention. Review of Research in Education, 41(1), 253-278. https://doi.org/10.3102/0091732X17690499

Howard, T. C. (2019). Why race and culture matter in schools: Closing the achievement gap in America's classrooms. Teachers College Press.

Jeynes, W. H. (2005). The effects of parental involvement on the academic achievement of 142 African American youth. The Journal of Negro Education, 74(3), 260-274.

Jackson, J. F., \& Moore, J. L. (2008). Introduction: The African American Male Crisis in Education: A Popular Media Infatuation or Needed Public Policy Response?. American Behavioral Scientist,51(7), 847-853. https://doi.org/10.1177/0002764207311992

Jones, K., Mixon, J. R., Henry, L., \& Butcher, J. (2017). Response to cultures continuum and the development of intercultural responsiveness (IR). Education Leadership Review of Doctoral Research, 4, 1-16.

Khalifa, M. (2018). Culturally responsive school leadership. Race and Education Series. Harvard Education Press.

Ladson-Billings, G. (1998). Just what is critical race theory and what's it doing in a nice field like education? International Journal of Qualitative Studies in Education, 11(1), 7-24. https://doi.org/10.1080/095183998236863

Journal of Contemporary Issues in Education, 2020, 15(2), pp. 36-49. 
Lincoln, Y. S., \& Guba, E. G. (1985). Naturalistic inquiry. Beverly Hills, CA: Sage Publications, Inc.

Losen, D. J., \& Skiba, R. J. (2010). Suspended education: Urban middle schools in crisis. Montgomery, AL: Southern Poverty Law Center

Maguire, M., \& Delahunt, B. (2017). Doing a thematic analysis: A practical, step-by-step guide for learning and teaching scholars. AISHE-J: The All Ireland Journal of Teaching and Learning in Higher Education, 9(3), 3351-33514

Mallett, C. A. (2017). The school-to-prison pipeline: Disproportionate impact on vulnerable children and adolescents. Education and Urban Society, 49(6), 563-592. DOI: $10.1177 / 0013124516644053$

Marsh, L. (2018). Symbolic violence: School-imposed labeling in a "No-excuses" charter school. Penn GSE Perspectives on Urban Education, 15(1), 1-8.

Merriam, S. B., \& Grenier, R. S. (Eds.). (2019). Qualitative research in practice: Examples for discussion and analysis. John Wiley \& Sons.

Moustakas, C. (1994). Phenomenological research methods. Sage.

Noguera, P. A. (1997). Reconsidering the "crisis" of the Black male in America. Social Justice, 24(2) (68), 147-164.

Noguera, P.A. (2003). The trouble with Black boys: The role and influence of environmental and cultural factors on the academic performance of African American males. Urban Education, 38(4), 431-459. https://doi.org/10.1177/0042085903038004005

Orfield, G., \& Lee, C. (2005). Why segregation matters: Poverty and educational inequality. Civil Rights Project at Harvard University (The).

Peske, H., \& Haycock, K. (2006). Teaching inequality: How poor and minority students are shortchanged on teacher quality. The Education Trust.

Ramsook, L. (2018). A methodological approach to hermeneutic phenomenology. International Journal of Humanities and Social Sciences, 10(1), 14-24.

Rocque, M., \& Paternoster, R. (2011). Understanding the antecedents of the "School-to-Jail" link: The relationship between race and school discipline. Journal of Criminal Law and Criminology, 101(2), 633-665. Retrieved from http://www.questia.com

Sacks, L. (2019). The school-to-prison pipeline: The plight of African American males in special education. In Inclusion, equity and access for individuals with disabilities (pp. 6787). Palgrave Macmillan. https://doi.org/10.1007/978-981-13-5962-0_4

Schott Foundation for Public Education. (2015). Black Lives Matter: The Schott 50 state report on public education and Black males. Cambridge, MA: Michael Holzman

Skiba, R. J., Horner, R. H., Chung, C., Rausch, M. K., May, S. L., \& Tobin, T. (2011). Race is not neutral: A national investigation of African American and Latino disproportionality in school discipline. School Psychology Review, 40(1), 85-107. https://doi.org/10.1080/02796015.2011.12087730

Skiba, R. J., Arredondo, M. I., \& Williams, N. T. (2014). More than a metaphor: The contribution of exclusionary discipline to a school-to-prison pipeline. Equity \& Excellence in Education, 47(4), 546-564. https://doi.org/10.1080/10665684.2014.958965

Smith, R.A. (2005). Saving black boys. The School Administrator. January p. 16-25. https://prospect.org/special-report/saving-black-boys/

Smith, C. D. (2009). Deconstructing the pipeline: Evaluating school-to-prison pipeline equal protection cases through a structural racism framework. Fordham Urban Law Journal,

Journal of Contemporary Issues in Education, 2020, 15(2), pp. 36-49. 
36(5), 1009-1049.

Solórzano, D. G., \& Yosso, T. J. (2002). Critical race methodology: Counter-storytelling as an analytical framework for education research. Qualitative Inquiry, 8(1), 23-44. https://doi.org/10.1177/107780040200800103

Somers, C. L., Owens, D., \& Piliawsky, M. (2008). Individual and social factors related to urban African American adolescents' school performance. High School Journal, 91(3), $1-11$.

Stanley, D., \& Chambers, T. T. V. (2018). Tracking myself: African American high school students talk about the effects of curricular differentiation. International Journal of Education Policy and Leadership, 13(1), 1-16. https://doi.org/10.22230/ijepl.2018v13n1a748

Toldson, I. A., McGee, T., \& Lemmons, B. P. (2015). Reducing suspensions by improving academic engagement among school-age Black males. In Daniel Losen (Ed.) Closing the school discipline gap: Equitable remedies for excessive exclusion. (107-117). Teachers College Press

van Manen, M. (1997). Researching lived experience: Human science for an action sensitive pedagogy (2nd ed.). London, Canada: The Althouse Press.

Vivian, L. (2017). The influence of school segregation on students' educational achievement. Perspectives, 9(1), 11.

Welch, K., \& Payne, A. A. (2010). Racial threat and punitive school discipline. Social Problems, 57(1), 25-48. https://doi.org/10.1525/sp.2010.57.1.25

Williams, T. R, Davis, L. E., Miller-Cribbs, J., Saunders, J., \& Williams, J. H. (2002). Friends, family, and neighborhood: Understanding academic outcomes of African American youth. Urban Education, 37, 408-431. https://doi.org/10.1177/00485902037003006 